\title{
Article \\ Consumers' Adoption and Use of E-Currencies in Virtual Markets in the Context of an Online Game
}

\author{
Magdalena Gawron and Artur Strzelecki *(D) \\ Department of Informatics, University of Economics in Katowice, 40-287 Katowice, Poland; \\ magdalena.gawron@edu.uekat.pl \\ * Correspondence: artur.strzelecki@ue.katowice.pl
}

Citation: Gawron, M.; Strzelecki, A. Consumers' Adoption and Use of E-Currencies in Virtual Markets in the Context of an Online Game. J. Theor. Appl. Electron. Commer. Res. 2021, 16, 1266-1279. https://doi.org/10.3390/ jtaer16050071

Academic Editor: María

Teresa Ballestar

Received: 13 January 2021

Accepted: 12 April 2021

Published: 13 April 2021

Publisher's Note: MDPI stays neutral with regard to jurisdictional claims in published maps and institutional affiliations.

Copyright: (c) 2021 by the authors. Licensee MDPI, Basel, Switzerland. This article is an open access article distributed under the terms and conditions of the Creative Commons Attribution (CC BY) license (https:/ / creativecommons.org/licenses/by/ $4.0 /)$.

\begin{abstract}
Virtual worlds have created unique economies whose outcome is e-currencies, which link the electronic universe and reality. This article aims to examine how perceived usefulness, perceived ease of use, perceived risks, and perceived trust significantly impact consumers' virtual currencies' behaviour. The study tested and used an adapted TAM model in the context of virtual currencies using structural equation modelling. The partial least square method of structural equation modelling is employed to test the proposed research model. The study utilises an online survey to obtain data from 205 virtual currency consumers. The data set was analysed using SmartPLS 3 software. The results showed that the best predictor of consumers' intention to use virtual currencies is perceived usefulness, followed by perceived ease of use. Perceived trust predicts consumers' perceived usefulness and perceived ease of use. These findings reveal that virtual currencies are seen as useful and easy to use. Consumers trust them enough but notice the risks they carry. They can also accept problems associated with them when it comes to their intention to use them.
\end{abstract}

Keywords: e-currency; virtual market; virtual world; online games

\section{Introduction}

The virtual economy is a sector that affects the virtual world in which it is used. Real institutions recognise their role and importance. The amount of money invested in virtual worlds is enormous [1]. The market importance is acknowledgeable for all stakeholders, such as countries, producers, or consumers. An appropriate exploration of this area may increase profits in the future and improve conditions for users, investors, and game publishers. Restrictions that will or have already been imposed on the virtual market should be tailored to specific cases-the more knowledge there is on this still-young topic, the more adequate solutions will improve both worlds.

In this study, e-currencies are virtual currencies used in virtual worlds created in online games. The aim of this study is to investigate consumers' attitudes and behaviours when using e-currencies. The study tests an adapted version of F.Davis' TAM theory when consumers use e-currencies in virtual worlds [2]. Exploring the use of e-currencies is important because a growing number of consumers are using real money to spend time in virtual worlds.

The motivation to study consumers' adoption and use of e-currencies in virtual markets comes from the great interest in this in the context of online games. There has been research carried out on games' virtual currencies such as empirical analysis on currency stability [3] or cash-trade methods in online games [4]. These studies were conducted on virtual currencies by collecting data from user comments, studying the exchange rate of virtual currency or collecting players' behavioural data [5]. However, to the best of our knowledge, no studies directly asked consumers about virtual currencies using an adapted TAM method and partial least squares structural equation modelling (PLS-SEM).

The lack of research among consumers who would like to share their experiences with virtual currencies represents a literature gap. The referenced studies, if they were 
carried out among consumers, were conducted with the use of other study methods than are proposed in this study. In this work, we would like to fill this gap by providing unbiased data from virtual currencies' users on how they use and adopt it in the context of an online game, regarding the type of the game. With this in mind, we prepared a study among virtual currency users to fill the current gap in the literature. Using the wellestablished TAM method and PLS-SEM modelling, this paper aims to describe consumers' adoption of virtual currencies and awareness of their gambling issues. Consumers have different expectations of virtual currencies. The study explores which variables are the best predictors of consumers' intention to use virtual currencies and determines how consumers evaluate the risks attached to virtual currencies.

This study's contribution to general research on virtual currencies consists of collecting data from consumers who have used game currencies, have experience in role-playing, and have encountered different types of risks associated with game currencies. The state-ofthe-art research contains a model of external variables that impact intention to use virtual currencies in games. The data were gathered through a questionnaire survey for users of virtual currencies in games. The research's main finding is that the best predictor of consumers' intention to use virtual currencies is their perceived usefulness, followed by their perceived ease of use. Furthermore, perceived trust predicts consumers' perceptions of virtual currencies' usefulness and perceived ease of use.

The paper is organised as follows. Section 2 contains a review of the relevant literature on virtual markets, e-currencies in virtual markets, and challenges in e-currencies. Section 3 includes the survey concept and describes the development of the hypotheses and the model; Section 4 presents the measurement and structural assessment results of the model. Section 5 highlights the research's contribution, discusses its limitations, draws conclusions about the results, and proposes possible future research avenues.

\section{Literature Review}

\subsection{Virtual Markets}

Interest in the virtual market is contained in profits and rankings, which significantly impact our world. Investors see potential in them, and even the slightest stumble on the game scene has a significant impact on the stock market. Activision Blizzard stopped publishing data on its subscribers because it substantially impacted its market value [6]. Virtual markets consist of many types of digital games. These include mobile, console, computer or virtual space games [7]. The most significant profits can be seen in community games, such as massive multiplayer online games (MMO) [8]. These games' business model continuously adapts to players' changing world: from a subscription model to a free model with microtransactions [7]. In 2014, virtual goods alone were estimated at USD 3 billion [9]. Virtual goods are objects that are owned and used by users in virtual worlds [10].

Virtual worlds are becoming a large part of the lives of modern people [10]. Some people do not realise how much virtual media connect to our lives because they do not treat mobile applications or games within this category. They believe that spending time in front of a computer is fun for children, but it has already turned into entertainment for adults [11]. The average age of a typical player is 26 years. Most of them work full-time, which shows how important their experience in the virtual world is for them [12].

People live in communities. The three-dimensionality of virtual worlds such as World of Warcraft (WoW) or social worlds such as Second Life attract users [13]. Their social aspect can be classified as social media [14,15]. In 2015, World of Warcraft was the market leader in online gaming. Its model assumes a monthly subscription fee, but further add-ons must be purchased separately [16]. Another example is the second largest MMO in 2010, AION, which has 3.4 million subscribers. Its model is entirely different from the market leaders as it is based on free access and offers a paid starter and a premium package [17]. 


\subsection{E-Currencies in Virtual Markets}

Real-money trading (RMT), although it involves e-currencies as a kind of intermediary in transactions, allows success that could not be achieved so quickly under real circumstances [18]. The user's emotional attitude is often combined with the desire to achieve the best possible status [19]. Creating guilds, trading, collaborating or competing with other players are some of the many elements that encourage users to bond with a given virtual world.

Virtual worlds operate continuously: even when a user is logged out, other characters are still active [20]. This creates a kind of circle that makes it easier to see the world as real. Today, there are many virtual worlds. One should pay attention primarily to World of Warcraft, EverQuest, Eve Online, Second Life and The Sims [21]. The social integration offered in virtual worlds is based on trust. Users' avatars do not have to match their appearance in real life. No one is judged on this basis because-unlike in the real world-MMO players have complete control over their characters [22]. Factors that influence the success of e-currencies also include the element of randomness in virtual worlds that is most frequently encountered in games [23]. For example, acquired items are often categorised in terms of rarity. In this case, e-currencies allow one to reach a rare good faster if the player is not lucky [24]. Usually, the possibility of earning money in a regular game allows us to enjoy it, although this is not always the motivation to start playing a game [25].

A virtual currency is not precisely electronic money. The main differences are the lack of a physical equivalent, the lack of legal regulations by central banks, and the lack of specific control by state authorities [26]. It can be divided into two categories in terms of value: significant and insignificant. Monopoly money has value within the game, but it becomes an imaginary good in the real world. A significant currency can be exchanged for real money and thus influences reality [27]. Earnings in virtual worlds can be categorised as legal or illegal. Legal earnings are usually limited to making profits from live broadcasting (streaming), game journalism, or, when a game producer allows it, in-game transactions [28]. Users' time can be converted into e-currency. Every moment spent playing puts virtual money in a user's account [29]. However, this value is usually held by the service owner and cannot be legally converted into real money. Since the currency determines the time spent in a game, it is possible to "buy time" from other players in the form of items they have acquired or funds in the virtual world account [30]. Many players take this step because of pressure from other users, adapting to an upcoming event or reducing the game's unpleasant element, such as long-term experience or virtual good [31]. Some users value their characters by displaying them on auction portals. A gold-farmer profession consists of gaining in-game currency and selling it on auction portals for real money, which usually contravenes a game's regulations. However, this pays poorly: Chinese workers earn an average of USD 40 to USD 200 per month [32].

Despite so many exchange possibilities, it is impossible to exchange e-currencies in one game for e-currencies in another game [33]. Virtual worlds remain separate entities and do not connect. Sometimes, real money is also circulated by one company but can change from virtual currency to a given account's wallet. There are two options for buying a token for real money: exchange for in-game gold or funds in the user's account [34]. Some transactions in Second Life are subject to VAT, but this depends on the users' country of residence [35]. Many treat taxes as something related to the real world and do not think about introducing them to games. Earnings in games are an income and should be settled with income tax. This is important for two reasons. First, participants have ownership rights to their virtual goods. Secondly, any sale or exchange in a game represents the order's fulfilment and can be taxed [36].

\subsection{Challenges in E-Currencies}

The virtual currency market has advantages and disadvantages. Fighting countries against illegal transactions through inappropriate regulations is not proper behaviour in a 
globally marketed market. When the government fights, a black market is created, whose behaviour is peculiar. The impact of e-currency on the real world may harm the economy. Countries introduce regulations to harness the unknown virtual market. For example, China has introduced restrictions that limit conversions of e-currencies to real money only at the original interest rate. This comes down to a ban on free trade in virtual money [37].

Virtual worlds' hermetic nature allows developers to limit trading to a single platform, which usually concentrates on a particular world [33]. Each server can also have its economy adapted to the country. The rules of currency valuation are then only a matter of the world owner's strategy. This is possible due to the division of servers into specific regions. The value of the currency is different in each region [27]. Each server has its age, and its retail network structures vary greatly over time [38].

Real money trading (RMT) in games often harms user confidence. Users can often encounter feelings of uncertainty, expected regret, or too little trust during a transaction [18]. RMT itself is sometimes hidden in normal activities, such as sending gifts through a game's friends system [1]. This makes user tracking very limited [38]. The players themselves, however, believe that this type of trade harms the gameplay climate. Out of the 4957 people surveyed by mmorpg.com only $5.8 \%$ consider it positively, while $55.9 \%$ are strongly against it [39]. Every virtual world has its own rules and regulations. The developers of massively multiplayer online role-playing games (MMORPGs) act as supervisory authorities, central banks and final appeal institutions. It is up to them how the economy will function so that they can shape it for their own needs [40]. Players who are caught breaking the rules often have their accounts terminated or blocked. Others allow users to trade virtual currency outside the inner world. Such an example is Sony Online Entertainment-Station Exchange, which supports the game EverQuest II. Goods can be exchanged there in a fully secure environment [41].

The rules often specify that the account users have in the virtual world does not belong to them. However, this is not an obstacle for black market users to sell these accounts. Websites such as Allegro or eBay contain listings for characters, virtual goods, or entire player accounts for sale [42]. Currency for the game can also be bought. However, one should pay attention to the influence of these actions on the game's internal market. Despite prohibitions, gold farming is still developing. It has existed since 1987, and the stage of full marketisation ended over ten years ago in 2008 [43].

Often, in addition to a gold farmer's human equivalents, it can be seen that artificial intelligence (known as bots) automates the process. Bots are not limited by human needs but are easier to detect through unnatural or even schematic behaviour. They continuously repeat the same series of actions $[44,45]$.

\section{Materials and Methods}

\subsection{Data Collection}

A survey was published using SurveySwap.io and SurveyCircle., and we posted a link to the survey on Reddit to collect data. The only condition was to understand the concept of e-currency in virtual worlds. Informed consent was obtained from all individual participants included in the study. The survey was completely anonymous. All answers were collected in February 2020 using Google Forms. We removed answers where the standard deviation for all responses was 0.0 or without complete responses to every question. After data cleaning, 205 responses remained (Table 1). 
Table 1. Summary of survey responses.

\begin{tabular}{ccc}
\hline Gender & Number of Respondents & Percentage \\
\hline Female & 85 & $41.46 \%$ \\
Male & 118 & $57.56 \%$ \\
Other & 2 & $0.98 \%$ \\
\hline Education & Number of respondents & Percentage \\
\hline Primary education & 5 & $2.44 \%$ \\
Secondary education & 30 & $14.63 \%$ \\
Bachelor's degree & 109 & $53.17 \%$ \\
Master's degree & 47 & $22.93 \%$ \\
PhD & 14 & $6.83 \%$ \\
\hline Age & Number of respondents & Percentage \\
\hline $13-17$ & 5 & $2.44 \%$ \\
$18-24$ & 113 & $55.12 \%$ \\
$25-34$ & 69 & $33.66 \%$ \\
$35-44$ & 13 & $6.34 \%$ \\
$45-54$ & 3 & $1.46 \%$ \\
$55-64$ & 2 & $0.98 \%$ \\
$>65$ & 0 & $0.00 \%$ \\
\hline Total & 205 & $100 \%$ \\
\hline
\end{tabular}

The following factors can drive sample size in a structural equation model design [46]; significance level, statistical power, minimum coefficient of determination $\left(R^{2}\right.$ values) used in the model and a maximum number of arrows pointing at a latent variable. In our study, we determine a significance level of $5 \%$, a statistical power of $80 \%$, and we would like to discover $R^{2}$ values of at least 0.10 . Our model has a maximum number of arrows pointing at a latent variable as 4 . The minimum sample size for this setting is 147 [47].

There is no consensus in the literature regarding what would be the appropriate sample size for SEM. Simulation studies show that with normally distributed indicator variables and no missing data, a reasonable sample size for a simple confirmatory factor analysis (CFA) model is about $\mathrm{N}=150$ [48]. A widely accepted rule of thumb is sample size defined as ten times the largest number of structural paths directed at a particular construct in the structural model [49]. Therefore, we believe our sample size is sufficient to perform the PLS-SEM. We have collected 205 responses as a sample size; the criterion of minimum sample size is met.

As much as 53\% shows that e-currencies are of interest to people in college, usually after their bachelor's or master's degree (23\%). More than $50 \%$ are young people between 18 and 24 years old. The second-largest group are those who are between 25 and 34 years old (34\%). This overlaps with education, which is usually gained at this stage of life. The older part of the population, i.e., over 44 years old, is not interested in the study or does not have much contact with the topic it contains. It has not been possible to reach people from 65 years of age, so it can be said that virtual currencies are mainly the domain of young people, often in college or just after graduation. As the survey was available for everyone, the list of countries shows that language also matters. The English language choice to create the form decided the largest group of respondents from the United Kingdom (31\%) and the United States (11\%). From non-English speaking countries, the Kingdom of the Netherlands should be noted (16\%). Using SurveyCircle.com and its algorithm to collect reliable research data, one could expect such a large number of responses from mainly European countries.

Table 2 contains a list of survey questions, their acronyms and variables included in the basic model. All the questions used in the survey used a 7-point Likert scale. 
Table 2. Summary of variables and items measured in the survey.

Variable
$\begin{gathered}\text { Items } \\ \text { PU1: I think that virtual currency is very useful to my life } \\ \text { in general. }\end{gathered}$
$\begin{gathered}\text { PU2: I think that virtual currency is helpful to improve my } \\ \text { performance in the virtual world. }\end{gathered}$
PU3: I think that virtual currency is helpful to enhance the
effectiveness of my life.

\subsection{Hypotheses Development}

\subsubsection{Perceived Usefulness}

One of the definitions of perceived usefulness is that it is the degree to which an individual believes that using a particular system will improve performance [50]. However, it is better to say that using a given solution will affect the user's ability to use it to their advantage [51]. According to the consumer, the most important thing is the positive attitude of use to performance [52]. Usefulness affects many aspects of using a given service. Whether the customer will continue to use it depends on whether they find it useful and easy to use [53].

Hypothesis 1 (H1). The perceived usefulness positively affects the intention to use e-currency.

\subsubsection{Perceived Ease of Use}

The definition of perceived ease of use is consistent with perceived usefulness. According to Davis, it is the degree to which a person believes that using a given system will not require any effort [52]. Moore and Benbasat add that effort can be both physical and mental [50]. The use of virtual currencies depends on the users' desire. Ease of use and usefulness play a major role and decide whether the customer wants to get involved in the virtual world. As long as users are required less and pay off to use the service, they will be more inclined to stay [52].

Hypothesis 2 (H2). The perceived ease of use positively affects the intention to use the virtual currency.

\subsubsection{Perceived Risks}

The risk of buying virtual currencies consists of many factors. People worry about their privacy, the security of the payment system, the safety of the relationship between the manufacturers of virtual worlds, and the transaction's inconvenience [54]. Privacy 
issues usually consist of selling personal information to third parties or keeping track of buying habits. Too little knowledge, and therefore little ability to manage one's own data, deter customers [54]. The transaction raises concerns about the security of credit card or personal data. If the company does not have a good reputation, the user may be afraid of non-delivery or lack of contact after placing an order. Many reject the number of terms and conditions that must be agreed upon when placing an order [55]. The risks of virtual worlds mainly relate to immersion disorders [56]. The hermetic nature of these worlds also affects the difficulty of obtaining a return after the transaction. The goods themselves are virtual, so they cannot be touched, felt or sometimes even seen. The risk associated with this type of use of e-currency causes anxiety among users [54].

Hypothesis $\mathbf{3} \mathbf{( H 3 )}$. There is an impact of perceived risk on the intention to use e-currencies.

\subsubsection{Perceived Trust}

In real life, people ask themselves, "how do you know who to trust?" In the virtual world, the problem of trust is enormous. Its users treat a company managing a world with loyalty depending on its size, reputation and decisions made towards its customers [57]. The way the offer is presented is fundamental. The problem of understatement and illegibility makes the customer unable to trust a given manufacturer [58]. The issue of trust concerns privacy because the basis of the transaction is providing personal data. It follows that to ensure users' confidence, it is necessary to take care of securing their private information [59]. Then, a good business model and a secure payment system must be created [54].

Hypothesis 4 (H4). Perceived trust positively affects perceived usability.

Hypothesis 5 (H5). Perceived trust positively affects perceived ease of use.

\subsection{Model}

Structural equation modelling (SEM) is primarily a set of techniques for checking relationships between variables [49]. PLS (partial least squares) allows one to conduct tests for a small sample and predict indicators. It allows one to make hypotheses for variables that influence particular aspects of the model. The variables can be marked as factors or measured variables. The freedom of modelling enables a new look at existing theories [60].

PLS-SEM modelling consists of several stages. In addition to having data to start calculations, the quality of the model should be checked. It is necessary to determine whether the variables are of a reflective or formative type. After defining their type, the next stage is to test the hypotheses and check their relations [61].

Consumers' approach, trust and market analysis are changing under the media's influence, changes in the real and virtual world economy. Checking if features such as usefulness or ease of use affect the specific intention of use determine how e-currency is used. However, this is often due to the desire to improve character in terms of equipment or appearance. This does not impact the real world, apart from pay with real money, and many people decide to do so [62]. This study aims to see what qualities drive customers most and least. Whether or not virtual currencies contribute to the gambling business by linking them to paid and random loot boxes can influence customers' decisions. It is necessary to examine whether all the items included in the intention to use are taken into account by users. Figure 1 shows the basic version of the model without checking whether the measurements are relevant to the model. 


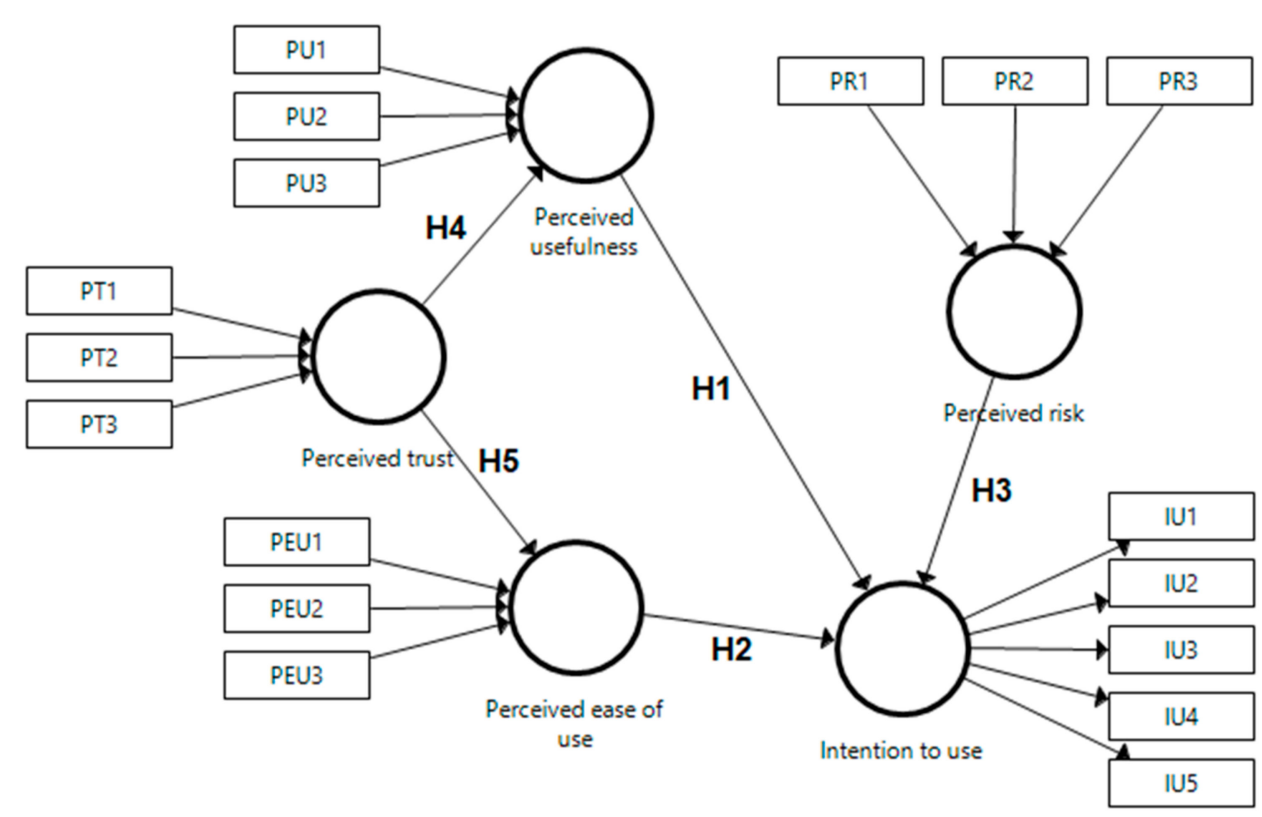

Figure 1. Model showing the impact of customer behaviour on e-currency purchases.

\section{Results}

Structural equations modelling used for this study was conducted with the help of SmartPLS 3. Accurate results are referred to as results of the PLS-SEM algorithm. The following options were used for the study: PLS algorithm, bootstrap and blindfolding. For the PLS algorithm, basic settings in the configuration were used: centroidal weighing scheme, 300 as a maximum number of iterations and stop criterion at the level of $10^{\wedge}-\mathrm{X}$ with selected 7. A total of 5000 subsamples for bootstrapping full version with bias-corrected and accelerated $(\mathrm{BCa})$ in two-tailed distribution were selected for bootstrap. Blindfolding remained in the default version, i.e., with the omission distance at level 7 [63].

\subsection{Measurement Model Assessment}

For reflective type variables, it is necessary to check their accuracy in terms of test results. The condition for accepting a given variable is that it has a load above the value of 0.70 . The average explained variance (AVE) helps determine whether the construct explains $50 \%$ of the data variance and the assumed AVE limit is a value from 0.50 [61].

In Table 3, there is one variable with four of the initial five items. Checking the loadings, and thus the reliability factor and AVE, concluded that the IU5 item (loading 0.609; reliability coefficient 0.370 ) is not important and should be removed from the model to improve the results. Loadings of the other items are standard and indicate their relevance. An additional condition fulfilled is the reliability factor. The mean explained variance (AVE) meets the assumed limit. Taking into account these three factors, it can be concluded that the variables are accurate.

Table 3. Reflective variable accuracy. AVE: average explained variance.

\begin{tabular}{ccccc}
\hline \multirow{2}{*}{ Variable } & Item & Loadings & Reliability Coefficient & AVE \\
\cline { 3 - 5 } & & $>\mathbf{0 . 7}$ & $>\mathbf{0 . 5}$ & $>\mathbf{0 . 5}$ \\
\hline \multirow{3}{*}{ IU } & IU1 & 0.815 & 0.664 & \\
& IU2 & 0.884 & 0.781 & 0.713 \\
& IU3 & 0.857 & 0.734 & \\
\hline
\end{tabular}


In addition to the accuracy, the reliability must also be checked. Based on the results in Table 4, verification of the intention to use can be continued. The composite reliability meets the condition with Cronbach's alpha. The reliability of the indicator is between the results of these two. The Cronbach alpha does not exceed the permissible level of 0.90. It is not possible to check discriminant validity for a single variable [64].

Table 4. Reliability of the reflective variable.

\begin{tabular}{cccc}
\hline \multirow{2}{*}{ Variable } & Composite Reliability $\boldsymbol{\rho c}$ & Reliability Indicator $\boldsymbol{\rho} A$ & Cronbach's Alpha \\
\cline { 2 - 4 } & $>\mathbf{0 . 7}$ & $>\mathbf{0 . 7}$ & $\mathbf{0 . 7 - 0 . 9}$ \\
\hline $\mathrm{IU}$ & 0.908 & 0.867 & 0.865 \\
\hline
\end{tabular}

Other variables in the model are the formative variables (Table 5). As in the case of the reflective variable, some of them were not important and were removed. This happened with the PU1 (weight -0.024 ; loading 0.755; variance inflation factor (VIF) 3.119) and PR1 (weight $-0.824 ;-0.409$; VIF 1.208 ) variables because their weights were too low to be relevant for modelling. Their remaining in the model was also not supported by a high load level because the weight value was not acceptable. It is recommended to remove unnecessary variables based on their weights to obtain a model consisting of significant connections alone [65]. Other variables and the level of their weights and loadings were confirmed as important by checking the $p$-value at 0.05 . All VIF values visible in Table 6 for the other variables are between 1 and 2.60. They do not exceed the condition that was 3 , so it can be concluded that there is no collinearity and no unnecessary variables in the model [66].

Table 5. Results for the formative variables.

\begin{tabular}{ccccc}
\hline Variable & Item & Weight & Loading & $p<0$.05 \\
\hline \multirow{2}{*}{ PU } & PU2 & 0.697 & 0.968 & Yes \\
& PU3 & 0.369 & 0.882 & Yes \\
\hline \multirow{2}{*}{ PT } & PT1 & 0.291 & 0.874 & Yes \\
& PT2 & 0.458 & 0.923 & Yes \\
& PT3 & 0.366 & 0.881 & Yes \\
\hline \multirow{2}{*}{ PEU } & PEU1 & 0.448 & 0.924 & Yes \\
& PEU2 & 0.380 & 0.906 & Yes \\
& PEU3 & 0.280 & 0.864 & Yes \\
\hline \multirow{2}{*}{ PR } & PR2 & 0.463 & 0.689 & Yes \\
& PR3 & 0.759 & 0.897 & Yes \\
\hline
\end{tabular}

Table 6. VIF values for the formative variables.

\begin{tabular}{cccc}
\hline Item & VIF & Item & VIF \\
\hline PEU1 & 2.559 & PT1 & 2.439 \\
PEU2 & 2.550 & PT2 & 2.518 \\
PEU3 & 2.344 & PT3 & 2.197 \\
PR2 & 1.097 & PU2 & 2.184 \\
PR3 & 1.097 & PU3 & 2.184 \\
\hline
\end{tabular}

After removing unnecessary and insignificant variables IU5, PU1 and PR1, the final calculated data are presented in Tables 3-6.

\subsection{Structural Model Assessment}

After cleaning the data and selecting the measurements, the results of the estimation should be reviewed. It turns out that the strongest relationships are between perceived 
trust and usefulness and trust with ease of use. Less relevant paths are already directly connected to the intention to use through risk, usefulness and ease of use.

The values in Table 7 highlight the T-statistics values for perceived trust (PT) $\rightarrow$ perceived ease of use (PEU) and PT $\rightarrow$ perceived usefulness (PU) paths. The magnitude of the $f^{2}$ effect size for PEU $\rightarrow$ intention to use (IU) and perceived risk (PR) $\rightarrow$ IU is considered small, PU $\rightarrow$ IU is considered medium, and the two remaining ones related to trust can be considered a large effect. All $p$-values are smaller than the assumed value of 0.05 , so it can be concluded that they are significant.

Table 7. Results supporting hypotheses.

\begin{tabular}{cccccc}
\hline Path & $\begin{array}{c}\text { Path } \\
\text { Coefficient }\end{array}$ & $\begin{array}{c}\text { BCa } \\
{[\mathbf{2 . 5 ; 9 7 . 5 ]} \%}\end{array}$ & T-Statistics & $\boldsymbol{f}^{\mathbf{2}}$ & $\begin{array}{c}\text { Confirmed } \\
\boldsymbol{p}<\mathbf{0 . 0 5}\end{array}$ \\
\hline $\mathrm{PEU} \rightarrow \mathrm{IU}$ & 0.278 & {$[0.135 ; 0.397]$} & 4.123 & 0.089 & Yes \\
$\mathrm{PR} \rightarrow$ IU & 0.177 & {$[0.025 ; 0.310]$} & 2.409 & 0.051 & Yes \\
$\mathrm{PT} \rightarrow$ PEU & 0.593 & {$[0.475 ; 0.675]$} & 12.107 & 0.541 & Yes \\
$\mathrm{PT} \rightarrow$ PU & 0.522 & {$[0.401 ; 0.621]$} & 9.486 & 0.375 & Yes \\
$\mathrm{PU} \rightarrow$ IU & 0.389 & {$[0.264 ; 0.511]$} & 6.053 & 0.173 & Yes \\
\hline
\end{tabular}

Table 8 contains additional methods of checking if the model is important. The values of the coefficient of determination $R^{2}$ are relatively low, but since the T-statistics are within the acceptable limits, $R^{2}$ can be considered significant [67].

Table 8. $R^{2}$ and $Q^{2}$ effect sizes.

\begin{tabular}{ccc}
\hline Variable & $\boldsymbol{R}^{2}$ & $Q^{2}$ \\
\hline IU & 0.379 & 0.262 \\
PEU & 0.351 & 0.275 \\
PU & 0.273 & 0.234 \\
\hline
\end{tabular}

The excess of cross-redundancy $Q^{2}$ determines the quality of the measurements in the equations [58]. The smaller the difference between the predicted and original values, the greater the criterion $Q^{2}$ and the model's prediction accuracy. If $Q^{2}$ is greater than 0 , it can be concluded that the prediction is significant [52]. The cross-referencing of the $Q^{2}$ only assumes that the values must be greater than 0 to be considered suitable. All results are between 0.230 and 0.280 .

\section{Discussion}

After confirming all the assumptions concerning the methodology, the results had to be analysed. It turns out that not all formative variables are relevant to the model. Consumers do not consider virtual currencies to be essential in life and do not feel insecure when buying. For this reason, PU1 and PR2 items were removed from the model. The perceived usefulness variables remaining in the model affect the intention to use. Their weights allow one to conclude that virtual currencies increase the efficiency of users' lives. Additionally, it can be assumed that the use of virtual worlds becomes easier. The path coefficient between perceived usefulness and intention to use is so high that it can be considered significant, confirming hypothesis $\mathrm{H} 1$, that the perceived usefulness positively affects the intention to use the virtual currency.

The path of perceived ease of use is also important for the model. Consumers stated that the use of e-currency is clear and understandable. Mental effort, which is used for many activities, is not required in this case. The purchase itself is seen as quite easy. None of the variables were eliminated at the stage of the relevance analysis. The result validates Hypothesis 2: "The perceived ease of use positively affects the intention to use the virtual currency". 
Only two of the perceived risk variables are left. Although people do not feel insecure when buying, they notice other disadvantages of these currencies. When used in roleplaying games, it can disturb the immersion and gameplay feeling of players. Users additionally notice that they are too much connected with the virtual world account. Despite a rather low ratio, it was left in the model. The hypothesis H3 has been confirmed because the perceived risk impacts the intention to use e-currencies.

The highest coefficients of paths have been observed between trust and usefulness and trust and ease of use. Hypotheses H4 and H5 are supported. The result validates Hypothesis 4: "The perceived trust positively impacts the perceived usefulness of the virtual currency" and Hypothesis 5: "The perceived trust positively impacts the perceived ease of use of the virtual currency". The least important for consumers is the safest way to buy virtual currencies, but they consider that the seller will take care of them because it is in their interest.

The only reflective variable, i.e., the intention to use, after analysis reveals that the assumption that virtual currencies increase the gambling phenomenon through loot boxes with paid, random content is irrelevant to the potential consumer. The remaining statements and their loads are high enough to leave them in the model. E-currencies allow, according to the respondents, one to improve their virtual equipment and user avatar. Another important assumption is that time is gold, and gold in virtual worlds allows one to enjoy the game in an advanced form faster. These resources can usually be obtained employing payments from the real world. The last item of this construct was the assumption that virtual currencies allow one to climb the ranking faster. The high load of this variable proves that this is one of the reasons for using virtual currencies.

All hypotheses were confirmed. Virtual currencies are seen as useful and easy to use. Consumers trust them enough but notice the risks they carry. They can also accept problems associated with them when it comes to their intention to use them.

This type of research can be used primarily in the field of computer, mobile, console and many other games. Knowledge of consumer opinions allows them to better adapt the offer to the virtual and real world's current situation. People are willing to pay more for some things and some less. The appropriate approach to the customers can change their view about the product or even the whole company. It is not without reason that companies conduct surveys from time to time to check what people think about them. In addition to the obvious values that developers are guided by, it is worth noting how virtual currencies affect their worlds. E-currencies disturb the immersion of the world in which they are introduced. Some games are based solely on stories and a sense of the universe. This study can help developers decide to introduce currencies into their world or introduce another measure to increase their earnings. It is also a seed of research that introduces better knowledge of their users about their product confidence.

The recipients of virtual currencies are mainly young people. Seniors were not interested in the study or did not know the virtual currency concept and, therefore, did not participate. This information may help people engaged in advertising these currencies or designing the entire economy under a given age group's beliefs. Creating a currency in this respect may be an interesting new solution in virtual worlds. Another issue is to reduce contribution to the purchase and use of virtual currencies. Designers who are responsible for designing interfaces should adapt them to the needs of specific consumer groups. The less effort a customer has to put into the purchase, the easier it is to accept e-currencies in this environment.

Respondents considered the issue of trust in relations with the seller of virtual currency to be necessary. Manufacturers should take care of this trust credit because it involves money. Most people trust the vendor and notice that they have a mutual profit in it. For this reason, they feel safe and feel that companies will take care of their stakeholders. This type of research also allows us to check how consumer confidence affects individual aspects of the company. Checking how the trust affects changes in payments, the approach to 
the brand and the corporation's employees themselves allows one to improve individual elements of the business so that everyone can cooperate.

To sum up, the most important thing is to balance both worlds. The virtual world cannot feel a violent impact on the economy, gameplay or any kind of rankings. On the other hand, the real world must accept the distinctiveness of the virtual universe.

\section{Conclusions}

The study aimed at identifying factors influencing the intention to use virtual currencies. It proposed an adapted TAM model tailored to fit the context of virtual currencies. Based on regression analysis, the results herein support the proposed model, as all of the five hypotheses were confirmed. The results have shown that perceived usefulness, and perceived ease of use positively impacted the intention to use. The perceived trust positively impacted the perceived usefulness and perceived ease of use, and perceived risk impacted the intention to use. The research results have provided reliable information for developers of virtual gaming worlds to make business decisions. Additionally, this study contributes to the research on the behavioural intention of using virtual currencies based on TAM. Therefore, this study has provided consumers' acceptance hints to virtual worlds developers while also opening up several new directions for further research.

The most important limitation that this study met was the small variety of people who took part in the survey. An interesting approach would undoubtedly be to analyse a group in one environment, for example, for one virtual world from a particular producer. This would give less general and more precise results because it would create specific questions based on one game. The variety of virtual worlds limits this study's application to the general public, and therefore it only contributes to the theory.

Author Contributions: Conceptualisation, M.G.; methodology, M.G.; software, M.G.; validation, M.G.; formal analysis, M.G.; investigation, M.G.; resources, M.G.; data curation, M.G.; writingoriginal draft preparation, M.G.; writing-review and editing, A.S.; visualisation, M.G.; supervision, A.S.; project administration, A.S.; funding acquisition, A.S. All authors have read and agreed to the published version of the manuscript.

Funding: This research received no external funding.

Institutional Review Board Statement: Not applicable.

Informed Consent Statement: Informed consent was obtained from all subjects involved in the study. Data Availability Statement: Not applicable.

Conflicts of Interest: The authors declare no conflict of interest.

\section{References}

1. Nazir, M.; Man Lui, C.S. A survey of research in real-money trading (RMT) in virtual world. Int. J. Virtual Communities Soc. Netw. 2017, 9, 34-53. [CrossRef]

2. Davis, F.D. A Technology Acceptance Model for Empirically Testing New End-User Information Systems: Theory and Results, Massachusetts Institute of Technology. Ph.D. Thesis, MIT Sloan School of Management, Cambridge, MA, USA, 1986.

3. Kim, T. The predecessors of bitcoin and their implications for the prospect of virtual currencies. PLoS ONE 2015, 10, e0123071. [CrossRef]

4. Holin, L.; Sun, C.-T. Cash trade in free-to-play online games. Games Cult. 2011, 6, 270-287. [CrossRef]

5. Xu, X.; Yang, X.; Lu, J.; Lan, J.; Peng, T.-Q.; Wu, Y.; Chen, W. Examining the effects of network externalities, density, and closure on in-game currency price in online games. Internet Res. 2017, 27, 924-941. [CrossRef]

6. Fernandes, L.V.; Castanho, C.D.; Jacobi, R.P. A survey on game analytics in massive multiplayer online games. In Proceedings of the 2018 17th Brazilian Symposium on Computer Games and Digital Entertainment (SBGames), Foz do Iguacu, Brazil, 29 October-1 November 2018; pp. 372-381.

7. Guo, H.; Hao, L.; Mukhopadhyay, T.; Sun, D. Selling virtual currency in digital games: Implications for gameplay and social welfare. Inf. Syst. Res. 2019, 30, 430-446. [CrossRef]

8. Zagała, K.; Strzelecki, A. eSports evolution in football game series. Phys. Cult. Sport. Stud. Res. 2019, 83, 50-62. [CrossRef]

9. Hamari, J.; Keronen, L. Why do people buy virtual goods: A meta-analysis. Comput. Hum. Behav. 2017, 71, 59-69. [CrossRef] 
10. Zhang, Y.; Huang, W. The research on consumer behavior of online games and its influencing factors. MATEC Web Conf. 2019, 267, 04010. [CrossRef]

11. Mijal, M. Gry komputerowe w organizacji-Uwarunkowania psychologiczne. Probl. Zarz. 2012, 10, 262-270. [CrossRef]

12. Yee, N. The labor of fun. Games Cult. 2006, 1, 68-71. [CrossRef]

13. Houliez, C.; Gamble, E. Dwelling in Second Life? A phenomenological evaluation of online virtual worlds. Virtual Real. 2013, 17, 263-278. [CrossRef]

14. Kaplan, A.M.; Haenlein, M. The fairyland of Second Life: Virtual social worlds and how to use them. Bus. Horiz. 2009, 52, 563-572. [CrossRef]

15. Lukowicz, K.; Strzelecki, A. User satisfaction on social media profile of e-sports organization. Mark. Manag. Innov. 2020, 61-75. [CrossRef]

16. Rigby, C.S.; Przybylski, A.K. Virtual worlds and the learner hero. Theory Res. Educ. 2009, 7, 214-223. [CrossRef]

17. Woo, K.; Kwon, H.; Kim, H.; Kim, C.; Kim, H.K. What can free money tell us on the virtual black market? In ACM SIGCOMM Computer Communication Review, Proceedings of the ACM SIGCOMM 2011 Conference, Toronto, ON, Canada, 15-19 August 2011; ACM: New York, NY, USA, 2011; pp. 392-393.

18. Constantiou, I.; Legarth, M.F.; Olsen, K.B. What are users' intentions towards real money trading in massively multiplayer online games? Electron. Mark. 2012, 22, 105-115. [CrossRef]

19. Fetscherin, M.; Lattemann, C. User acceptance of virtual worlds. J. Electron. Commer. Res. 2008, 9, $231-242$.

20. Cheng, M.-T.; Lin, Y.-W.; She, H.-C. Learning through playing Virtual Age: Exploring the interactions among student concept learning, gaming performance, in-game behaviors, and the use of in-game characters. Comput. Educ. 2015, 86, 18-29. [CrossRef]

21. Atlas, S.A. Inductive metanomics: Economic experiments in virtual worlds. J. Virtual Worlds Res. 2008, 1. [CrossRef]

22. Qin, H.; Patrick Rau, P.-L.; Salvendy, G. Measuring player immersion in the computer game narrative. Int. J. Hum. Comput. Interact. 2009, 25, 107-133. [CrossRef]

23. Gałka, P.; Strzelecki, A. How randomness affects player ability to predict the chance to win at PlayerUnknown's Battlegrounds (PUBG). Comput. Games J. 2021. [CrossRef]

24. Guo, Y.; Barnes, S. Virtual item purchase behavior in virtual worlds: An exploratory investigation. Electron. Commer. Res. 2009, 9, 77-96. [CrossRef]

25. Hofman-Kohlmeyer, M. Why people join virtual worlds of computer games? Qualitative research amongst polish users. In CBU International Conference Proceedings 2019, Proceedings of the International Conference on Innovations in Science and Education, Prague, Czech Republic, 20-22 March 2019; Open Journal Systems: Prague, Czech Republic, 2019; Volume 7, pp. 130-136.

26. Mackiewicz, P.; Musiał, M. Rozwój wirtualnych systemów monetarnych. Financ. Sci. 2014, 1, 132-141. [CrossRef]

27. Živić, N.; Andjelković, I.; Özden, T.; Dekić, M.; Castronova, E. Results of a massive experiment on virtual currency endowments and money demand. PLoS ONE 2017, 12, e0186407. [CrossRef]

28. Guo, Y.; Barnes, S. Purchase behavior in virtual worlds: An empirical investigation in Second Life. Inf. Manag. 2011, 48, 303-312. [CrossRef]

29. Wohn, D.Y. Spending real money. In Proceedings of the 32nd Annual ACM Conference on Human Factors in Computing Systems-CHI'14, Toronto, ON, Canada, 26 April-1 May 2014; ACM Press: New York, NY, USA, 2014; pp. $3359-3368$.

30. Rossi, L. MMORPG guilds as online communities-Power, space and time: From fun to engagement in virtual worlds. SSRN Electron. J. 2012. [CrossRef]

31. Gałuszka, D. Gold farming: Preliminary dissertation on the basis of Polish gold farmer case study. Perspekt. Kult. 2015, 12, 92-109.

32. Nardi, B.; Kow, Y.M. Digital imaginaries: How we know what we (think we) know about Chinese gold farming. First Monday 2010. [CrossRef]

33. Guo, J.; Chow, A.; Wigand, R.T. Virtual wealth protection through virtual money exchange. Electron. Commer. Res. Appl. 2011, 10, 313-330. [CrossRef]

34. Kim, Y.B.; Kang, K.; Choo, J.; Kang, S.J.; Kim, T.; Im, J.; Kim, J.-H.; Kim, C.H. Predicting the currency market in online gaming via lexicon-based analysis on its online forum. Complexity 2017, 2017, 4152705. [CrossRef]

35. Messinger, P.R.; Stroulia, E.; Lyons, K.; Bone, M.; Niu, R.H.; Smirnov, K.; Perelgut, S. Virtual worlds-Past, present, and future: New directions in social computing. Decis. Support Syst. 2009, 47, 204-228. [CrossRef]

36. Mennecke, B.E.; Terando, W.D.; Janvrin, D.J.; Dilla, W.N. It's just a game, or is it? Real money, real income, and real taxes in virtual worlds. Commun. Assoc. Inf. Syst. 2007, 20, 134-141. [CrossRef]

37. Jedlińska, R.J. Wpływ gospodarki wirtualnej na gospodarke realna-Wybrane zagadnienia. Pr. Nauk. Uniw. Ekon. Wrocławiu 2015, 104-116. [CrossRef]

38. Lee, E.; Woo, J.; Kim, H.; Kim, H.K. No silk road for online gamers! In Proceedings of the 2018 World Wide Web Conference on World Wide Web-WWW'18, Lyon, France, 23-27 April 2018; ACM Press: New York, NY, USA, 2018; pp. $1825-1834$.

39. Kawale, J.; Pal, A.; Srivastava, J. Churn Prediction in MMORPGs: A social influence based approach. In Proceedings of the 2009 International Conference on Computational Science and Engineering, Vancouver, BC, Canada, 29-31 August 2009; pp. 423-428.

40. Jin, W.; Sun, Y.; Wang, N.; Zhang, X. Why users purchase virtual products in MMORPG? An integrative perspective of social presence and user engagement. Internet Res. 2017, 27, 408-427. [CrossRef]

41. Shim, K.J.; Srivastava, J. Behavioral profiles of character types in EverQuest II. In Proceedings of the 2010 IEEE Conference on Computational Intelligence and Games, Copenhagen, Denmark, 18-21 August 2010; pp. 186-194. 
42. Greengard, S. Social games, virtual goods. Commun. ACM 2011, 54, 19-22. [CrossRef]

43. Heeks, R. Understanding "Gold Farming" and real-money trading as the intersection of real and virtual economies. J. Virtual Worlds Res. 1970, 2. [CrossRef]

44. Kang, A.R.; Jeong, S.H.; Mohaisen, A.; Kim, H.K. Multimodal game bot detection using user behavioral characteristics. Springerplus 2016, 5, 523. [CrossRef] [PubMed]

45. Kwon, H.; Mohaisen, A.; Woo, J.; Kim, H.K.; Kim, Y.; Lee, E.J. Crime scene reconstruction: Online gold farming network analysis. IEEE Trans. Inf. Forensics Secur. 2016, 1. [CrossRef]

46. Hair, J.F., Jr.; Sarstedt, M.; Hopkins, L.; Kuppelwieser, G.V. Partial least squares structural equation modeling (PLS-SEM). Eur. Bus. Rev. 2014, 26, 106-121. [CrossRef]

47. Kock, N. Minimum sample size estimation in PLS-SEM: An application in tourism and hospitality research. In Applying Partial Least Squares in Tourism and Hospitality Research; Ali, F., Rasoolimanesh, S.M., Cobanoglu, C., Eds.; Emerald Publishing Limited: Bingley, UK, 2018; pp. 1-16, ISBN 9781787566996.

48. Muthén, L.K.; Muthén, B.O. How to use a Monte Carlo study to decide on sample size and determine power. Struct. Equ. Model. A Multidiscip. J. 2002, 9, 599-620. [CrossRef]

49. Hair, J.F.; Hult, G.T.M.; Ringle, C.; Sarstedt, M. A Primer on Partial Least Squares StructuralEquation Modeling (PLS-SEM), 2nd ed.; SAGE Publications, Inc.: Thousand Oaks, CA, USA, 2017; ISBN 9781483377445.

50. Moore, G.C.; Benbasat, I. Development of an instrument to measure the perceptions of adopting an information technology innovation. Inf. Syst. Res. 1991, 2, 192-222. [CrossRef]

51. Pańkowska, M.; Pyszny, K.; Strzelecki, A. Users' adoption of sustainable cloud computing solutions. Sustainability 2020, $12,9930$. [CrossRef]

52. Davis, F.D. Perceived usefulness, perceived ease of use, and user acceptance of information technology. MIS Q. 1989, 13, 319. [CrossRef]

53. Hamid, A.A.; Razak, F.Z.A.; Bakar, A.A.; Abdullah, W.S.W. The effects of perceived usefulness and perceived ease of use on continuance intention to use e-government. Procedia Econ. Financ. 2016, 35, 644-649. [CrossRef]

54. Miyazaki, A.D.; Fernandez, A. Consumer perceptions of privacy and security risks for online shopping. J. Consum. Aff. 2001, 35, 27-44. [CrossRef]

55. Jo Black, N.; Lockett, A.; Winklhofer, H.; Ennew, C. The adoption of internet financial services: A qualitative study. Int. J. Retail Distrib. Manag. 2001, 29, 390-398. [CrossRef]

56. Olczyk, A. "Your character has been robbed. Do you want to sue the other player?" Polskie prawo karne a "kradzież" przedmiotu w grze komputerowej. Replay Pol. J. Game Stud. 2014, 1, 107-117.

57. Jarvenpaa, S.; Tractinsky, N.; Vitale, M. Consumer trust in an Internet store. Inf. Technol. Manag. 2000, 1, 45-71. [CrossRef]

58. Hoffman, D.L.; Novak, T.P.; Peralta, M. Building consumer trust online. Commun. ACM 1999, 42, 80-85. [CrossRef]

59. Liu, C.; Marchewka, J.T.; Lu, J.; Yu, C.-S. Beyond concern-A privacy-trust-behavioral intention model of electronic commerce. Inf. Manag. 2005, 42, 289-304. [CrossRef]

60. Schumacker, R.; Lomax, R.G. A Beginner's Guide to Structural Equation Modeling, 4th ed.; Routledge: New York, NY, USA, 2016.

61. Sarstedt, M.; Ringle, C.M.; Hair, J.F. Partial least squares structural equation modeling. In Handbook of Market Research; Homburg, C., Klarmann, M., Vomberg, A.E., Eds.; Springer International Publishing: Cham, Switzerland, 2017; pp. 1-40, ISBN 978-1-45221744-4.

62. Hamari, J.; Alha, K.; Järvelä, S.; Kivikangas, J.M.; Koivisto, J.; Paavilainen, J. Why do players buy in-game content? An empirical study on concrete purchase motivations. Comput. Human Behav. 2017, 68, 538-546. [CrossRef]

63. Ringle, C.M.; Wende, S.; Becker, J.-M. SmartPLS 3. Bönningstedt: SmartPLS GmbH. Available online: http://www.smartpls.com (accessed on 15 January 2021).

64. Henseler, J.; Ringle, C.M.; Sarstedt, M. A new criterion for assessing discriminant validity in variance-based structural equation modeling. J. Acad. Mark. Sci. 2015, 43, 115-135. [CrossRef]

65. Petter, S.; Straub, D.; Rai, A. Specifying formative constructs in information systems research. MIS Q. 2007, 31, 623. [CrossRef]

66. Freckleton, R.P. Dealing with collinearity in behavioural and ecological data: Model averaging and the problems of measurement error. Behav. Ecol. Sociobiol. 2011, 65, 91-101. [CrossRef]

67. Cohen, J. Statistical Power Analysis for the Behavioral Sciences; Routledge: London, UK, 2013; ISBN 9780203771587. 